Article

\title{
Metal-Organic Frameworks to Metal/Metal Oxide Embedded Carbon Matrix: Synthesis, Characterization and Gas Sorption Properties
}

\author{
Jiun-Jen Chen ${ }^{1}$, Ya-Ting Chen ${ }^{2}$, Duraisamy Senthil Raja ${ }^{2}$, Yu-Hao Kang ${ }^{1}$, Pen-Chang Tseng ${ }^{1}$ \\ and Chia-Her Lin ${ }^{2,3}, *$ \\ ${ }^{1}$ Green Energy \& Environment Research Laboratories, Industrial Technology Research Institute, \\ Hsinchu 310, Taiwan; E-Mails: JiunJenChen@itri.org.tw (J.-J.C.); derekkang@itri.org.tw (Y.-H.K.); \\ PenChangTseng@itri.org.tw (P.-C.T.) \\ 2 Department of Chemistry, Chung Yuan Christian University, Chung-Li 320, Taiwan; \\ E-Mails: a00510225@hotmail.com (Y.-T.C.); senthilraja1985@gmail.com (D.S.R.) \\ ${ }^{3}$ R\&D Center for Membrane Technology \& Research Center for Structure of Matter, \\ Chung Yuan Christian University, Chung-Li 320, Taiwan \\ * Author to whom correspondence should be addressed; E-Mail: chiaher@cycu.edu.tw; \\ Tel.: +886-3-265-3315; Fax: +886-3-265-3399.
}

Academic Editor: Rafael Luque

Received: 5 July 2015 / Accepted: 11 August 2015 / Published: 19 August 2015

\begin{abstract}
Three isostructural metal-organic frameworks, (MOFs), [Fe(OH)(1,4-NDC)] (1), $[\mathrm{Al}(\mathrm{OH})(1,4-\mathrm{NDC})](2)$, and $[\mathrm{In}(\mathrm{OH})(1,4-\mathrm{NDC})](3)$ have been synthesized hydrothermally by using 1,4-naphthalene dicarboxylate (1,4-NDC) as a linker. The MOFs were characterized using various techniques and further used as precursor materials for the synthesis of metal/metal oxide nanoparticles inserted in a carbon matrix through a simple thermal conversion method. The newly synthesized carbon materials were characterized by scanning electron microscopy, transmission electron microscopy, energy-dispersive X-ray spectroscopy analysis, powder X-ray diffraction and BET analysis. The results showed that the MOF-derived carbon composite materials maintained the morphology of the original MOF upon carbonization, and confirmed the insertion of metal/metal oxide particles in the carbon matrix.
\end{abstract}


Keywords: metal-organic frameworks; 1,4-naphthalene dicarboxylate; nanoporous carbon; metal oxide nanoparticle; gas sorption

\section{Introduction}

Metal/metal oxide nanoparticles have demonstrated distinct properties from their bulk materials and have shown promising applications in many fields such as catalysis [1], magnetism [2] and biochemistry [3]. Though extensive research has been done, the preparation of these nanomaterials still suffers from the aggregation problem. In order to resolve the aggregation issue, a new strategy has been developed in which these nanoparticles are dispersed into carbon matrices such as porous carbon, carbon nanotubes and graphenes [1-3]. The carbon matrices can not only block the nanoparticles from aggregation, but also modify their properties [1-4].

On the other hand, metal-organic frameworks (MOFs) are the new types of porous hybrid functional materials that are constructed by metal ions or metal clusters and organic linkers. Because of their high porosities and tunable structural properties, they have wide functional applications in terms of catalysis [5,6], gas storage [7,8], sensors [9], biomedicine [10], and so on. Apart from the use of MOFs as crystalline porous materials, the utilization of MOFs as a precursor for metal/metal oxide nanoparticle-embedded carbon frameworks has been researched actively in recent years [11-16]. The subject has become of particular interest for functional applications such as catalysis, gas storage materials, anode materials for lithium-ion batteries, etc. [13-16]. After the report by Q. Xu et al. on the carbonization of MOF-5 [11], various methods have been reported to synthesize materials that contain metal/metal oxide nanoparticle-embedded porous carbon matrix from MOF precursors [17-20]. Since carbon, metal and oxygen atoms are arranged periodically at the atomic level within MOF structures, the MOFs can be converted into metal/metal oxide nanoparticle-embedded carbon frameworks with a certain degree of permanent porosity, which is much useful for the aforementioned applications.

Further, the synthesis of pure porous carbon materials has also been done using MOF as a precursor approach, which needs to remove the metal/metal oxide nanoparticles formed in situ. This can be done using many methods such as vaporization at high temperature, washing with an acid solution and so on. However, our aim is to synthesize the dispersed metal/metal oxide nanoparticles in porous carbon matrices without removing the metal particles formed in situ during calcination because of the fact that the MOFs are highly ordered materials, and the carbonized MOFs prepared from these MOFs are expected to induce homogeneously dispersed metal/metal oxide nanoparticles in the resulting porous carbon matrices. Furthermore, MOFs with numerous structural topologies and tunable pores will enable us to construct a variety of carbonized MOFs with different degrees of metal/metal oxide nanoparticle-embedded porous carbon matrices for various applications [21].

Though a few articles have been published on the synthesis of the dispersed metal $/ \mathrm{metal}$ oxide nanoparticles in porous carbon matrices from MOFs, the synthesis of metal/metal oxide nanoparticle-embedded porous carbon hybrid functional materials using a simple, one-step thermal conversion is still a challenge. Hence, herein we report three new metal/metal oxide embedded porous carbon hybrid functional materials from three MOFs ([Fe(OH)(1,4-NDC)] (1), [Al(OH)(1,4-NDC)] 
(2), and [ $\operatorname{In}(\mathrm{OH})(1,4-\mathrm{NDC})](3))$ of 1,4-naphthalene dicarboxylate (1,4-NDC) using a simple, one-step thermal cracking method. Further, the MOFs and their metal/metal oxide embedded carbon hybrid materials were characterized using various physico-chemical techniques, and their gas sorption properties have been studied.

\section{Experimental Section}

All reagents were commercially available and used as received without further purification. In a typical synthesis of the MOFs, the mixture of $\mathrm{FeCl}_{3}(0.162 \mathrm{~g}, 1.0 \mathrm{mmol})$ or $\mathrm{Al}\left(\mathrm{NO}_{3}\right)_{3} \cdot 9 \mathrm{H}_{2} \mathrm{O}(0.375 \mathrm{~g}$, $1.0 \mathrm{mmol})$ or $\mathrm{In}\left(\mathrm{NO}_{3}\right)_{3} \cdot x \mathrm{H}_{2} \mathrm{O}(0.301 \mathrm{~g}, 1.0 \mathrm{mmol}), \mathrm{H}_{2}-1,4-\mathrm{NDC}(0.108 \mathrm{~g}, 0.5 \mathrm{mmol})$, and $\mathrm{H}_{2} \mathrm{O}(10 \mathrm{~mL})$ was placed in a $23 \mathrm{~mL}$ Teflon autoclave and then heated at $180{ }^{\circ} \mathrm{C}$ for 1 day. After filtering off and washing with distilled water, powder samples of MOFs were obtained. 1: color, white; yield, $0.104 \mathrm{~g}$; elemental analysis, found/calcd.: C, 39.60/40.13; H, 4.16/4.21\% for $\mathbf{1} \cdot 4 \mathrm{H}_{2} \mathrm{O}$. 2 : color, white; yield, $0.117 \mathrm{~g}$; elemental analysis, found/calcd.: C, 49.24/49.00; $\mathrm{H}, 3.67 / 3.77 \%$ for $2 \cdot 2 \mathrm{H}_{2} \mathrm{O}$. 3: color, white; yield, $0.113 \mathrm{~g}$; elemental analysis, found/calcd.: C, 38.12/38.64; $\mathrm{H}, 2.65 / 2.70 \%$ for $3 \cdot 1.5 \mathrm{H}_{2} \mathrm{O}$.

Conversely, the synthesis of metal/metal oxide nanoparticles within a porous carbon matrix involves a direct carbonization method using the above synthesized MOFs as precursors. The MOFs $(0.200 \mathrm{~g})$ were taken in a silica boat and then placed in a tube furnace and heated from room temperature to $800{ }^{\circ} \mathrm{C}$ under $\mathrm{N}_{2}$ gas with a heating rate of $5^{\circ} \mathrm{C} \cdot \mathrm{min}^{-1}$ to carbonize the MOFs. After reaching the target temperature $\left(800{ }^{\circ} \mathrm{C}\right)$, the temperature was maintained at $800^{\circ} \mathrm{C}$ for $5 \mathrm{~h}$, then cooled down to room temperature with a cooling rate of $1^{\circ} \mathrm{C} \cdot \mathrm{min}^{-1}$. The final black-colored powder products were further characterized.

\section{Results and Discussion}

The simple hydrothermal reactions of $\mathrm{H}_{2}-1,4-\mathrm{NDC}(0.5 \mathrm{mmol})$ with corresponding metal salts $(1.0 \mathrm{mmol})$ yielded the new MOFs. The new MOFs were initially characterized by elemental analysis, which agrees well with theoretical values. The as-synthesized MOFs may contain guest $\mathrm{H}_{2} \mathrm{O}$ molecules which are removed by heating of these MOFs to $180{ }^{\circ} \mathrm{C}$ for $12 \mathrm{~h}$ under vacuum $\left(\sim 10^{-3}\right.$ torr $)$; the phase purity of the bulk materials were independently confirmed by powder X-ray diffraction (PXRD) measurements (Figure 1). Comparing the PXRD patterns of as-synthesized 1-3 with calculated PXRD patterns of reported aluminum naphthalenedicarboxylate (Al-1,4-NDC) MOF material [22] confirms that the these new MOFs (1-3) have the same type of structural architecture as Al-1,4-NDC (Figure 1a-c). Further comparison of these PXRD pattern of activated MOFs with one another showed that the three new MOFs are isostructural to each other (Figure 1d).

It is to be noted that the diffraction peaks of compound $\mathbf{1}$ and $\mathbf{3}$ at $8.2^{\circ}$ showed a slight shift from the calculated PXRD of Al-1,4-NDC, which may be due to the difference in the ionic radius of the metal ions $\left(\mathrm{Al}^{3+}<\mathrm{Fe}^{3+}<\mathrm{In}^{3+}\right)$.

The shape and microstructure of the resulting MOFs (1-3) were investigated via scanning electron microscopy (SEM) and images are presented in Figure 2. The SEM images of the compounds show that they are crystalline materials with an elongated block shape, with individual particle sizes of about $30 \mu \mathrm{m}, 3 \mu \mathrm{m}$, and $15 \mu \mathrm{m}$ (for $\mathbf{1}, \mathbf{2}$ and $\mathbf{3}$, respectively). 

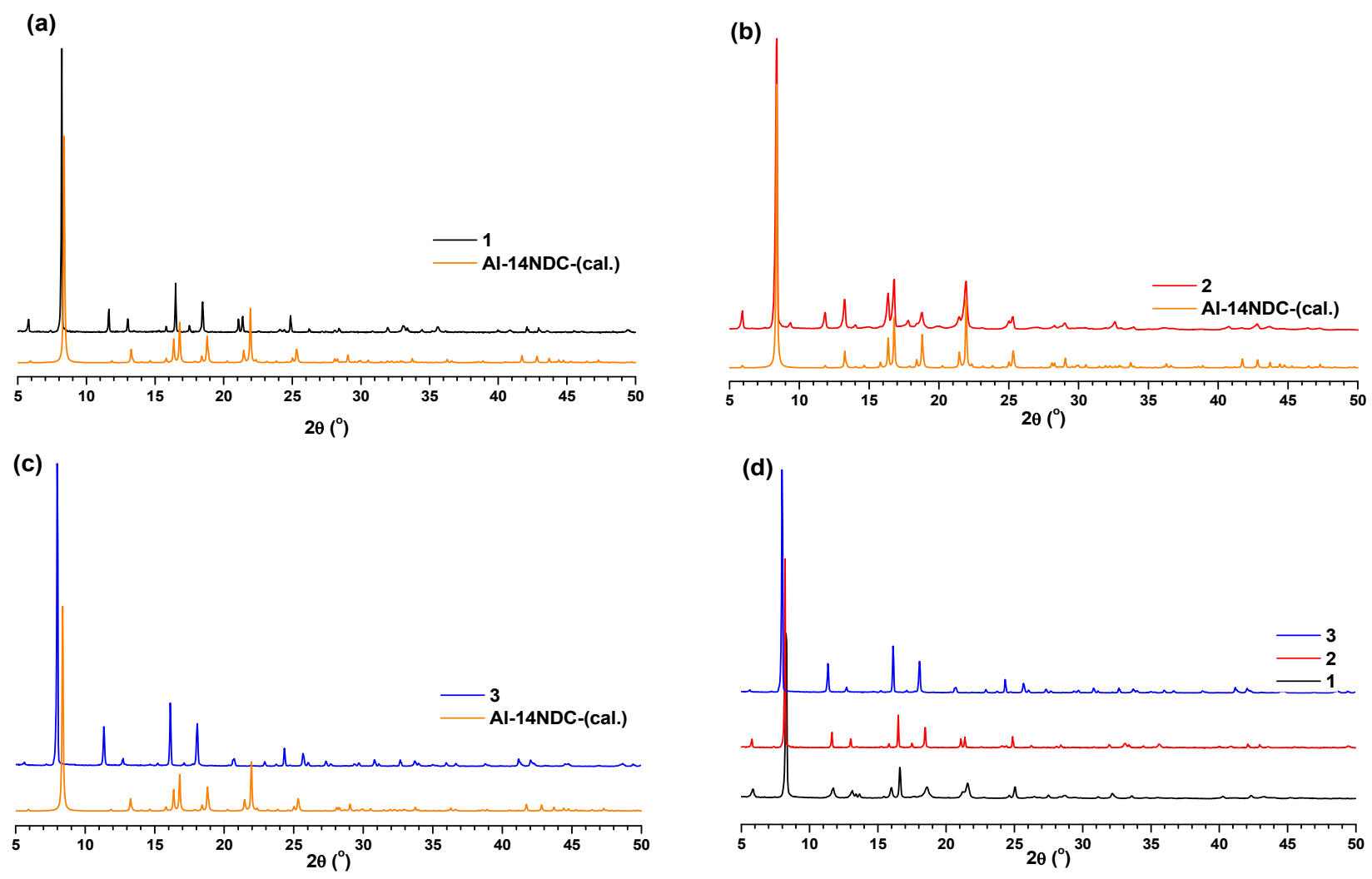

Figure 1. The comparison of PXRD patterns of as-synthesized MOFs, (a) 1, (b) 2 and (c) 3 with simulated PXRD pattern of reported Al-1,4-NDC; (d) the comparison of PXRD patterns of activated MOFs.

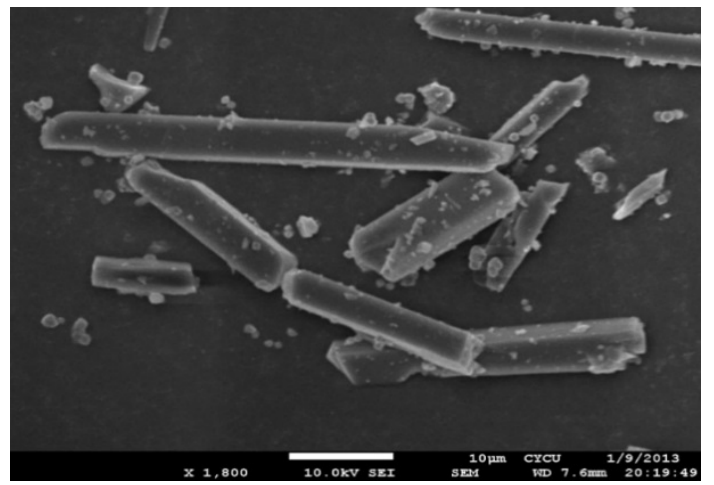

(a)

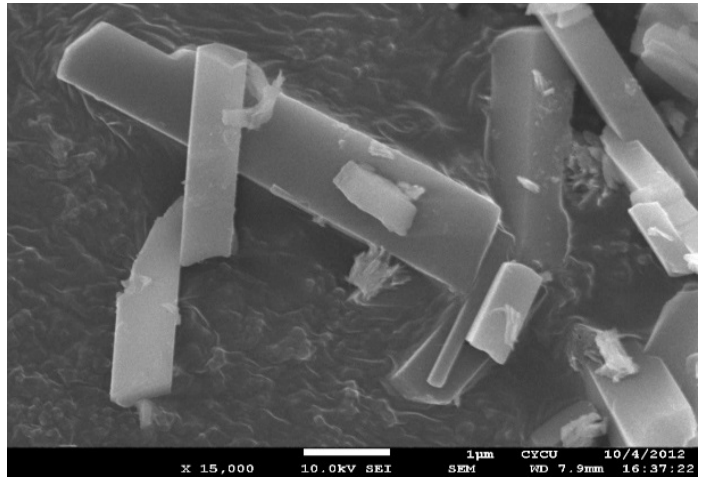

(b)

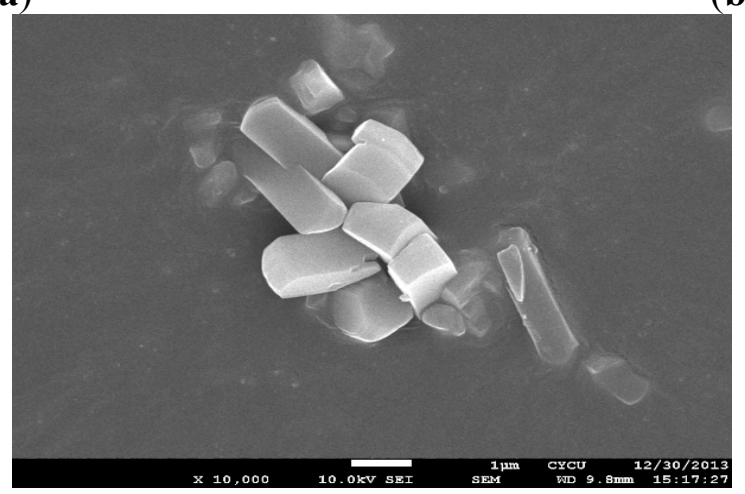

(c)

Figure 2. The SEM images of $\mathbf{1}(\mathbf{a}), \mathbf{2}(\mathbf{b})$ and $\mathbf{3}$ (c). 
In order to study the thermal properties of the MOFs, the TGA measurements for the compounds were performed under $\mathrm{N}_{2}$ atmosphere, and the results are shown in Figure $\mathrm{S} 1$. The slight weight loss observed initially (up 30-150 ${ }^{\circ} \mathrm{C}$ ) for all the compounds are may be due to the presence of a small amount of lattice water molecules. TGA studies indicated that $\mathbf{1}$ and $\mathbf{2}$ are quite stable up to $300{ }^{\circ} \mathrm{C}$ (compound $\mathbf{3}$ is stable up to $250{ }^{\circ} \mathrm{C}$ ). These TGA observations have further been confirmed through various in situ temperature PXRD measurements for all the compounds (Figures S2-S4). The various temperature PXRD data of Fe-MOF indicated that 1 was converted to $\mathrm{Fe}_{2} \mathrm{O}_{3}$ on heating to temperatures of $350{ }^{\circ} \mathrm{C}$ and above (Figure S2), whereas the MOFs 2 and $\mathbf{3}$ were converted to their respective metal oxides $\left(\mathrm{Al}_{2} \mathrm{O}_{3}\right.$ and $\mathrm{In}_{2} \mathrm{O}_{3}$ ) on heating to $400{ }^{\circ} \mathrm{C}$ (Figures S3 and S4). Further, the compounds were heated at various temperatures for one hour and the images of the compounds 1-3 after calcination at various temperature are given in Figures S5-S7, which show that the compounds did not undergo much color change up to $300{ }^{\circ} \mathrm{C}$ due to their high thermal stability. The calcined products of $\mathbf{1 - 3}$ at $600{ }^{\circ} \mathrm{C}$ were characterized using PXRD measurements and compared with calculated PXRD patterns of their corresponding metal oxides. The results indicated that compounds $\mathbf{1}$ and $\mathbf{3}$ were converted to their corresponding metal oxides $\left(\mathrm{Fe}_{2} \mathrm{O}_{3}\right.$ and $\mathrm{In}_{2} \mathrm{O}_{3}$, respectively) during calcination at $600{ }^{\circ} \mathrm{C}$ for one hour (Figure 3), whereas the Al-MOF was converted to an unidentified amorphous phase material (Figure S8).

(a)

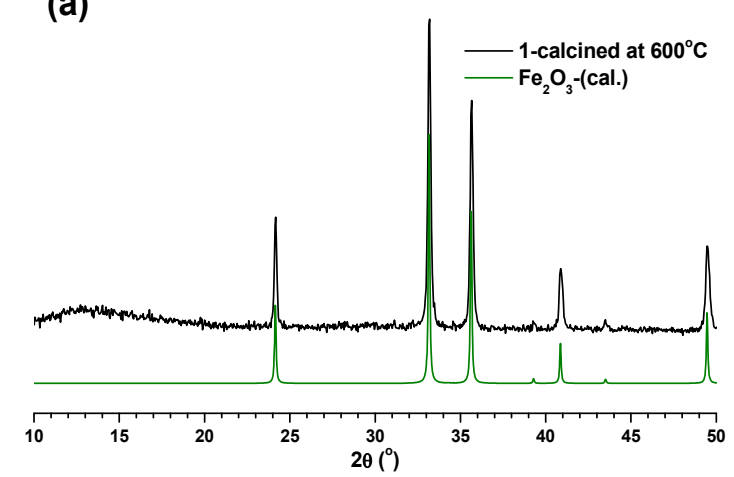

(b)

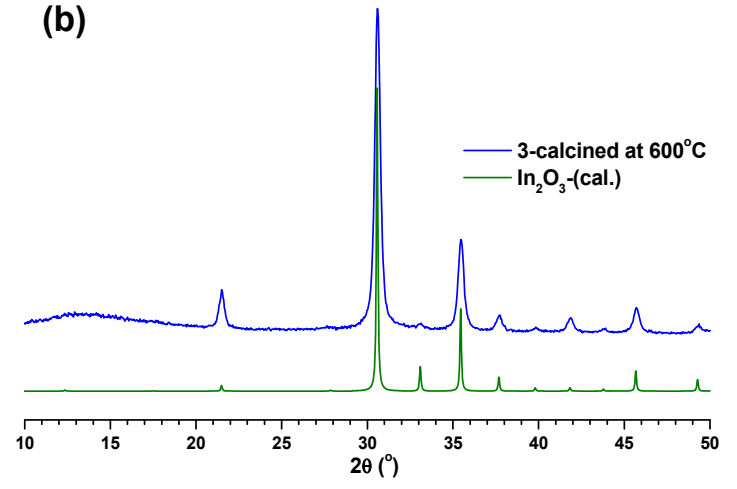

Figure 3. Comparison of PXRD patterns of $\mathbf{1}$ (a) and $\mathbf{3}$ (b) calcined at $600{ }^{\circ} \mathrm{C}$ with calculated PXRD pattern of their respective metal oxides.

The porous properties of the MOFs have been analyzed using $\mathrm{N}_{2}$ gas sorption measurements at $77 \mathrm{~K}$, which are shown in Figure 4. The results showed that compound $\mathbf{2}$ has a type-I adsorption isotherm which is characteristic of microporous material, and the BET and Langmuir surface area of 2 were calculated to be 155 and $162 \mathrm{~m}^{2} / \mathrm{g}$, respectively. The $\mathrm{N}_{2}$ adsorption isotherms of $\mathbf{1}$ and $\mathbf{3}$ indicated the non-porous nature of these materials, which may be due to the bigger ionic radius of the $\mathrm{Fe}^{3+}$ and $\mathrm{In}^{3+}$ metal ions than that of $\mathrm{Al}^{3+}$. However, the $\mathrm{CO}_{2}$ gas sorption measurements showed that compounds 1 and $\mathbf{3}$ have a porous nature. 


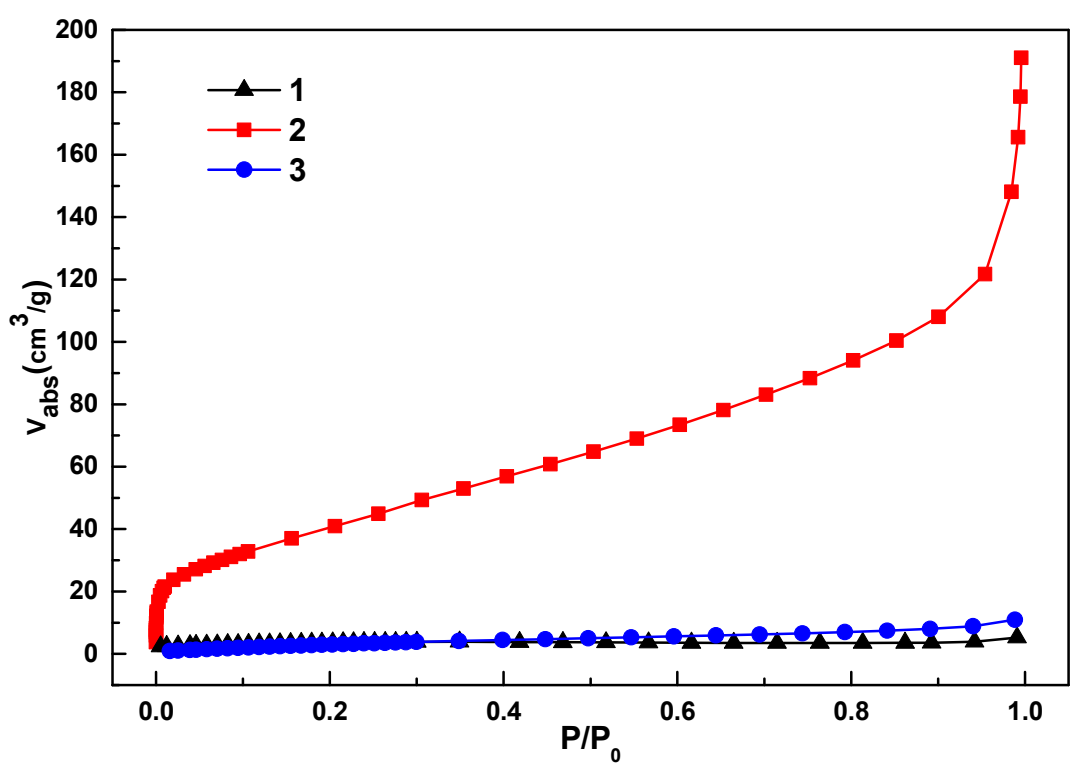

Figure 4. The $\mathrm{N}_{2}$ gas adsorption isotherms for $\mathbf{1}-\mathbf{3}$ at $77 \mathrm{~K}$.

The $\mathrm{CO}_{2}$ gas sorption isotherms for the compounds $\mathbf{1}-\mathbf{3}$ at $273 \mathrm{~K}$ and $298 \mathrm{~K}$ are given in Figures S9-S11. Compounds 1-3 exhibited $\mathrm{CO}_{2}$ adsorption of $1.30 \mathrm{mmol} / \mathrm{g}, 2.80 \mathrm{mmol} / \mathrm{g}$, and $2.29 \mathrm{mmol} / \mathrm{g}$, respectively, at $273 \mathrm{~K}, 1 \mathrm{~atm}$; whereas $0.76 \mathrm{mmol} / \mathrm{g}, 1.57 \mathrm{mmol} / \mathrm{g}$, and $1.27 \mathrm{mmol} / \mathrm{g}$ of $\mathrm{CO}_{2}$ adsorption were observed for compounds $\mathbf{1 - 3}$, respectively, at $298 \mathrm{~K}$ and $1 \mathrm{~atm}$.

In order to prepare metal/metal oxide nanoparticle-embedded carbon materials, the MOFs were used as templates. In a typical carbonization procedure, MOFs $(\mathbf{1}-\mathbf{3})$ were calcined at $800{ }^{\circ} \mathrm{C}$ under nitrogen gas flow for $5 \mathrm{~h}$. The final products were characterized with the aid of various techniques. The carbonized products from $\mathbf{1}, \mathbf{2}$ and $\mathbf{3}$ are designated as $\mathbf{1 c}, \mathbf{2 c}$ and $\mathbf{3 c}$, respectively. Compounds 1c-3c were initially characterized using PXRD measurements. The PXRD pattern matching of 1c with Fe and $\mathrm{Fe}_{3} \mathrm{C}$ (Figure 5a) clearly indicated the presence of iron and iron carbide particles inside the carbon matrix of 1c. At the same time, the PXRD pattern of 2c revealed its amorphous nature (Figure S12). Interestingly, the PXRD pattern matching of $3 \mathbf{c}$ with the theoretical PXRD patterns of In and $\operatorname{In}_{2} \mathrm{O}_{3}$ (Figure 5b) suggested the presence of indium and indium oxide particles inside the carbon matrix of $\mathbf{3 c}$.

(a)

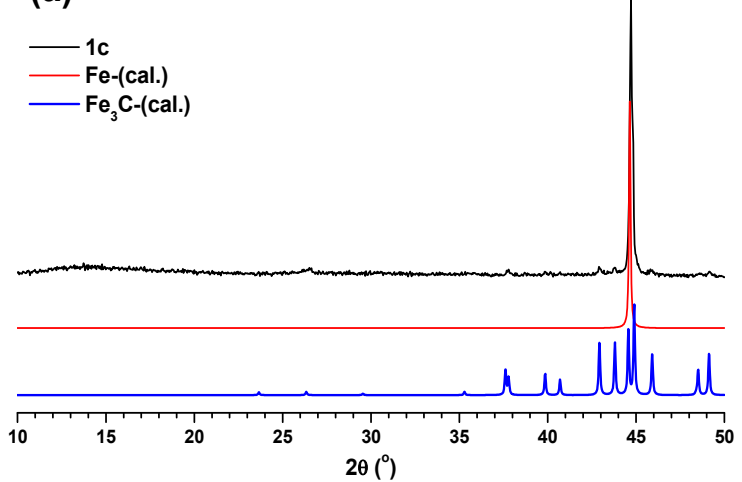

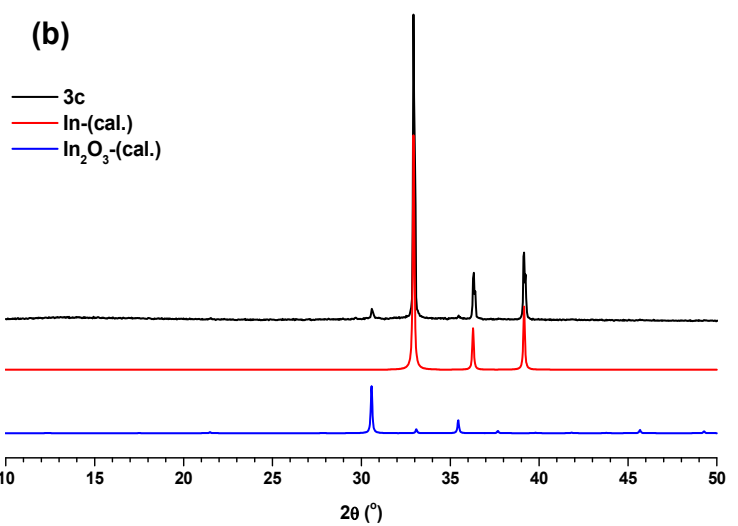

Figure 5. (a) Comparison of PXRD pattern of $1 \mathbf{c}$ with calculated PXRD patterns of Fe and $\mathrm{Fe}_{3}$ C. (b) Comparison of PXRD pattern of $3 \mathbf{c}$ with calculated PXRD patterns of $\operatorname{In}$ and $\mathrm{In}_{2} \mathrm{O}_{3}$. 
Further investigation of the local structure of the synthesized carbon materials $(\mathbf{1 c}-\mathbf{3 c})$ was carried out via Raman spectroscopy. Raman spectra of the obtained carbon samples are shown in Figure 6, exhibiting D and G bands centered around $1320 \mathrm{~cm}^{-1}$ and $1600 \mathrm{~cm}^{-1}$, respectively, which is due the disordered carbon structures and the stretching vibrations in opposite directions of two carbon atoms in a graphene sheet. The relative ratios of the $\mathrm{G}$ band to the $\mathrm{D}$ band $\left(I_{G} / I_{D}\right)$ were found to be 1.11 , 1.15 and 1.18 for $\mathbf{1 c}, \mathbf{2 c}$ and $\mathbf{3 c}$, respectively, suggesting that in all samples the graphene sheets were not well-developed and the local carbon structures contained both graphitic and disordered carbon atoms [23].

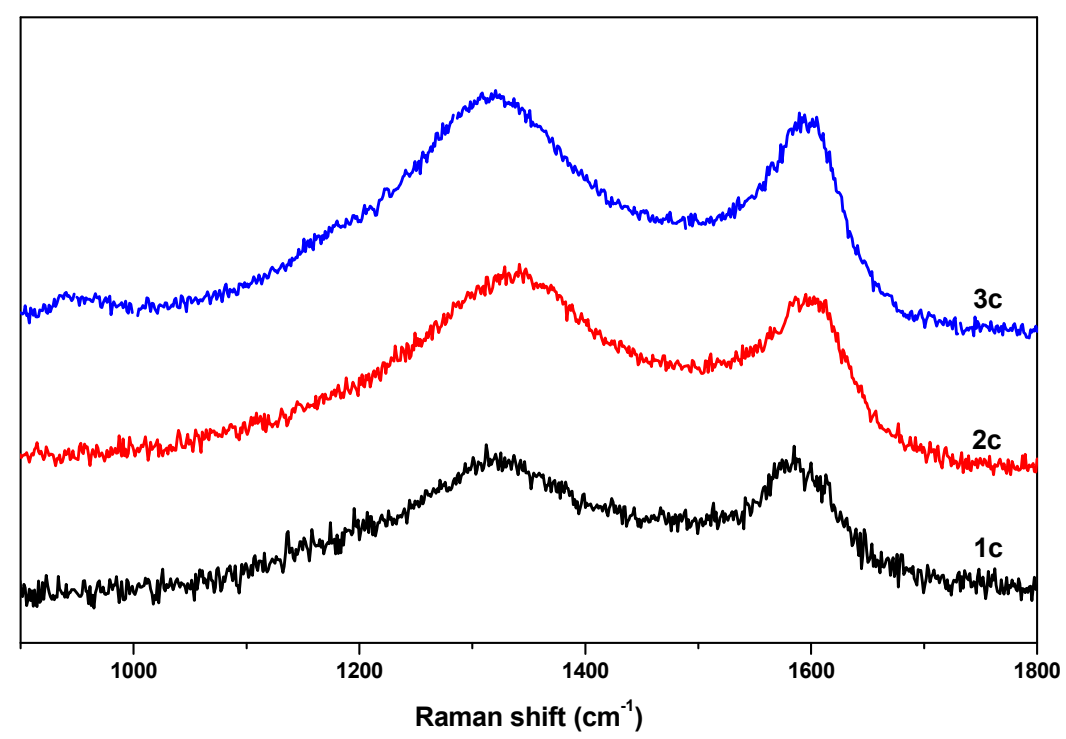

Figure 6. Raman spectra of the obtained nanoporous carbon samples.

Since compound 1c exhibited a strong interaction with a magnetic field (Figure S13), we were unable to characterize it further using SEM, TEM or energy dispersive X-ray spectroscopy (EDS) analysis. The SEM and TEM images of $\mathbf{2 c}$ and $\mathbf{3 c}$ (Figure 7) suggested that the obtained nanoporous carbons retained a typical crystal morphology similar to that of the parent MOFs. Further, the SEM and TEM images of 3c revealed that the surface of nanoporous carbon samples was embedded with indium oxide nanoparticles (Figure 3b,d). 

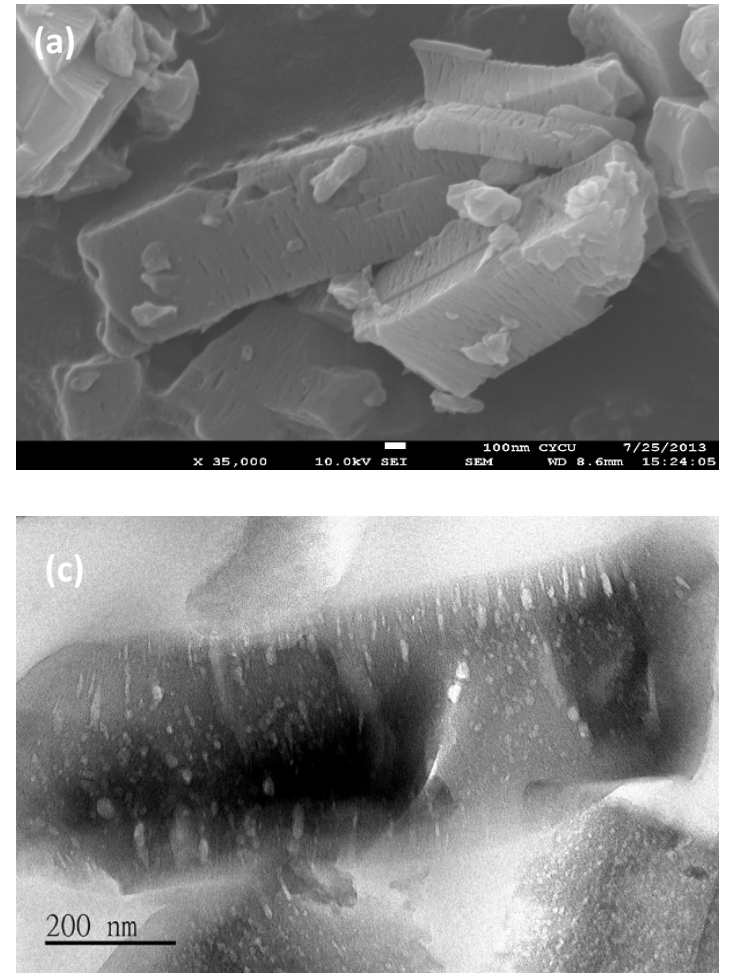
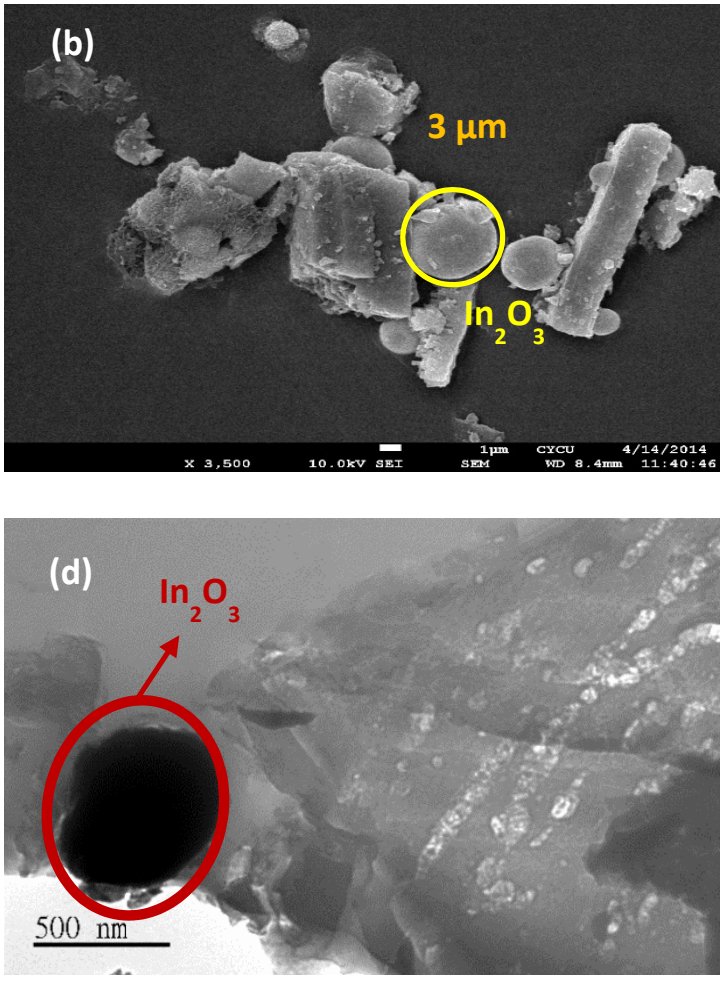

Figure 7. The SEM images of $\mathbf{2 c}(\mathbf{a})$, and $\mathbf{3 c}(\mathbf{b})$ and the TEM images of $\mathbf{2 c}(\mathbf{c})$, and $\mathbf{3 c}(\mathbf{d})$.

The composition of the carbon matrix and the metal oxide nanoparticles were confirmed through EDS analysis, and the results are given in Figures 8 and S14. Surprisingly, the EDS analysis of 2c showed the presence of aluminum oxide nanoparticles inside the carbon matrix (Figure 8). On the other hand, the results of EDS analysis of $\mathbf{3 c}$ at two different SEM image locations clearly confirms the presence of $\mathrm{In}_{2} \mathrm{O}_{3}$ in the carbon framework of $\mathbf{3 c}$ (Figure S14).

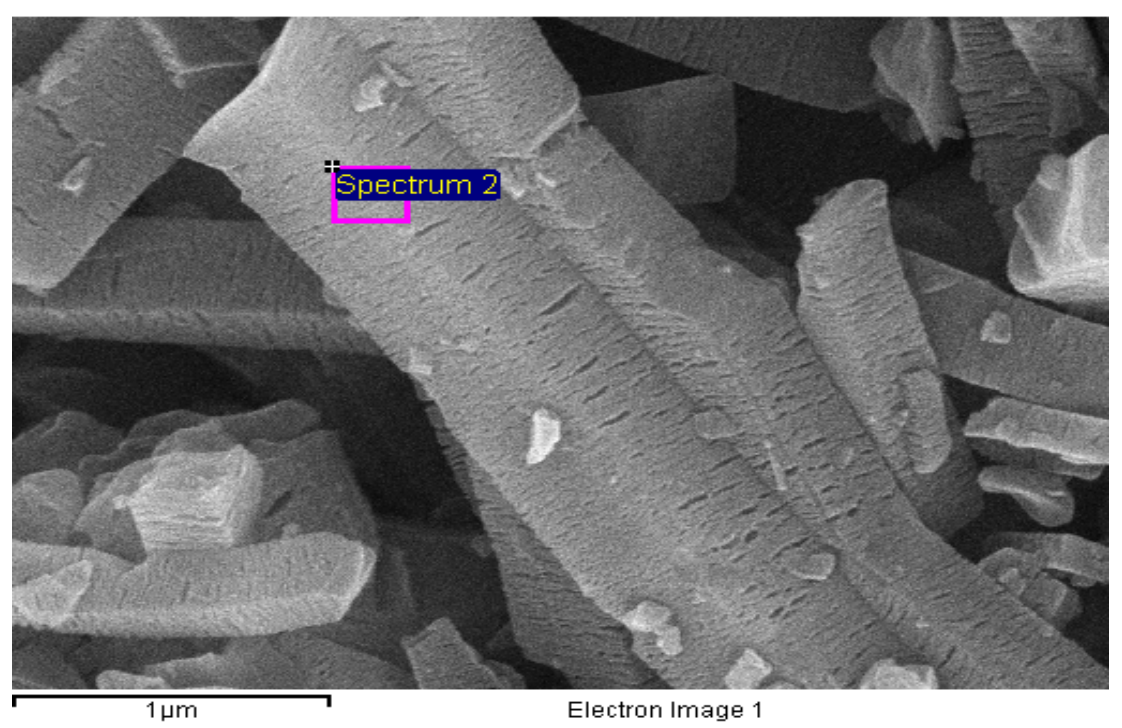

Figure 8. Cont. 


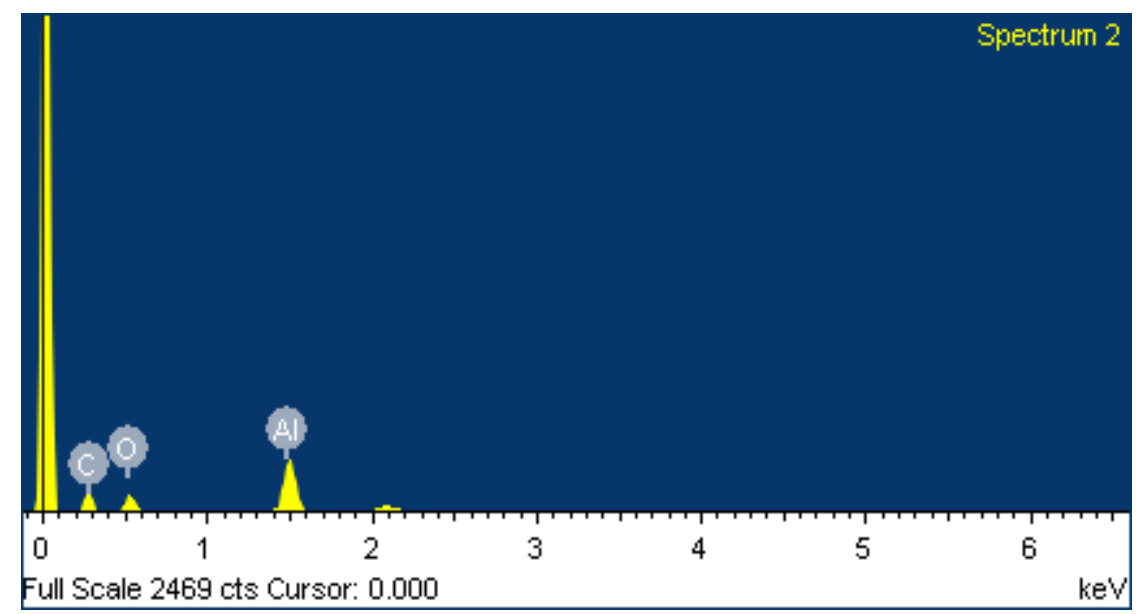

\begin{tabular}{ccc}
\hline Element & Weight (\%) & Atomic (\%) \\
\hline C & 45.36 & 58.85 \\
O & 24.22 & 23.59 \\
Al & 30.42 & 17.57 \\
\hline
\end{tabular}

Figure 8. The EDS analysis results for 2c.

Nitrogen gas adsorption analysis was used to further characterize the nanoporous structure of 1c, 2c and 3c (Figure 9). The shape of the isotherms indicated the existence of both micropores and mesopores. The steep increase at low relative pressure indicates the presence of the micropores. The isotherms showed a small hysteresis, which is typical for the presence of spherical mesopores randomly connected with weak microporosity. The analyzed pore characteristics of the carbon materials are summarized in Table 1. It is interesting to note that the porous properties of the carbon materials are better than that of their parent MOF materials. This may be due to the fact that some of the linker units of the MOFs have been removed in the form of $\mathrm{CO}_{2}$ gas during the carbonization process, which makes the resulting carbon materials more porous than the parent MOF materials.

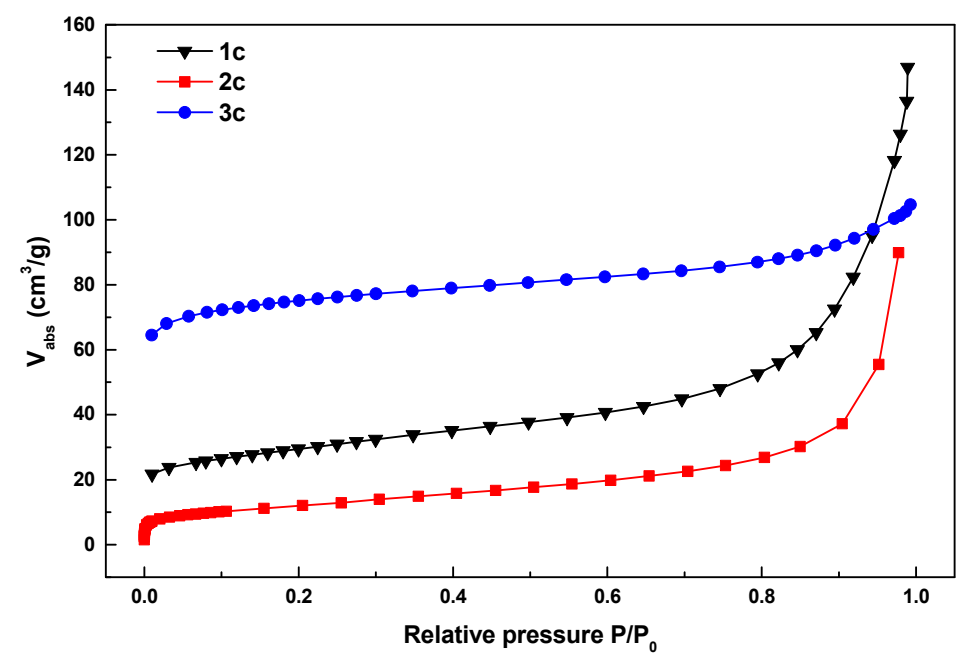

Figure 9. The $\mathrm{N}_{2}$ gas adsorption isotherms for $\mathbf{1 c}-\mathbf{3 c}$ at $77 \mathrm{~K}$. 
Table 1. Pore characteristics of the synthesized nanoporous carbon materials.

\begin{tabular}{cccc}
\hline Materials & $\begin{array}{c}\text { BET Surface Area } \\
\left(\mathbf{m}^{\mathbf{2}} / \mathbf{g}\right)\end{array}$ & $\begin{array}{c}\text { Langmuir Surface Area } \\
\left(\mathbf{m}^{\mathbf{2}} \mathbf{g}\right)\end{array}$ & $\begin{array}{c}\text { Total Pore Volume } \\
\left(\mathbf{c m}^{\mathbf{3}} / \mathbf{g}\right) \mathbf{P} / \mathbf{P}_{\mathbf{0}} \sim \mathbf{0 . 9 9}\end{array}$ \\
\hline $\mathbf{1 c}$ & 155 & 261 & 0.28 \\
$\mathbf{2 c}$ & 100 & 149 & 0.21 \\
$\mathbf{3 c}$ & 236 & 342 & 0.16 \\
\hline
\end{tabular}

\section{Conclusions}

In summary, Fe-, Al-, and In-MOFs based on a 1,4-NDC linker have been prepared and characterized. Using these MOFs as precursor materials, metal/metal oxide nanoparticle-inserted nanoporous carbons were prepared via simple direct carbonization without using any additional carbon sources. The PXRD, SEM, TEM, EDS and nitrogen sorption measurements confirm the dispersion of metal/metal oxide nanoparticles in the resulting nanoporous carbon materials. It can be expected that these newly synthesized carbon composite materials have promising prospects for application in supercapacitors.

\section{Supplementary Materials}

Supplementary materials can be accessed at: http://www.mdpi.com/1996-1944/8/8/5336/s1.

\section{Acknowledgments}

Financial assistance received from the Bureau of Energy of the Ministry of Economic Affairs, Taiwan; Ministry of Science and Technology, Taiwan (MOST103-2632-M-033-001-MY3 and MOST104-2113-M-033-006); and Chung-Yuan Christian University are gratefully acknowledged.

\section{Author Contributions}

C.-H.L. conceived and designed the experiments; J.-J.C. and Y.-T.C. performed the experiments and analyzed the data; Y.-H.K. and P.-C.T. contributed reagents/materials/analysis tools; D.S.R. wrote the paper.

\section{Conflicts of Interest}

The authors declare no conflict of interest.

\section{References}

1. Tong, X.; Qin, Y.; Guo, X.; Moutanabbir, O.; Ao, X.; Pippel, E.; Zhang, L.; Knez, M. Enhanced Catalytic activity for methanol electro-oxidation of uniformly dispersed nickel oxide nanoparticles-carbon nanotube hybrid materials. Small 2012, 8, 3390-3395. [CrossRef] [PubMed]

2. Sun, X. Microstructure and magnetic properties of carbon-coated nanoparticles. J. Dispersion Sci. Technol. 2003, 24, 557-567. [CrossRef] 
3. Kim, T.-H.; Lee, K.-B.; Choi, J.-W. 3D graphene oxide-encapsulated gold nanoparticles to detect neural stem cell differentiation. Biomaterials 2013, 34, 8660-8670. [CrossRef] [PubMed]

4. Miyanaga, S.; Yasuda, H.; Hiwara, A.; Nakumura, A.; Sakai, H. Pyrolysis of polymer complexes leading to air-stable ultrafine metal particles uniformly dispersedin a carbon matrix. J. Macromol. Sci. Part. A Chem. 1990, 27, 1347-1361. [CrossRef]

5. Wang, C.; de Krafft, K.E.; Lin, W. Pt nanoparticles @ photoactive metal-organic frameworks: Efficient hydrogen evolution via synergistic photoexcitation and electron injection. J. Am. Chem. Soc. 2012, 134, 7211-7214. [CrossRef] [PubMed]

6. Zhou, T.; Du, Y.; Borgna, A.; Hong, J.; Wang, Y.; Han, J.; Zhang, W.; Xu, R. Post-synthesis modification of a metal-organic framework to construct a bifunctional photocatalyst for hydrogen production. Energy Environ. Sci. 2013, 6, 3229-3234. [CrossRef]

7. Li, J.-R.; Kuppler, R.J.; Zhou, H.-C. Selective gas adsorption and separation in metal-organic frameworks. Chem. Soc. Rev. 2009, 38, 1477-1504. [CrossRef] [PubMed]

8. Li, J.-R.; Sculley, J.; Zhou, H.-C. Metal-organic frameworks for separations. Chem. Rev. 2012, 112, 869-932. [CrossRef] [PubMed]

9. Kreno, L.E.; Leong, K.; Farha, O.K.; Allendorf, M.; Van Duyne, R.P.; Hupp, J.T. Metal organic framework materials as chemical sensors. Chem. Rev. 2011, 112, 1105-1125. [CrossRef] [PubMed]

10. Horcajada, P.; Gref, R.; Baati, T.; Allan, P.K.; Maurin, G.; Couvreur, P.; Ferey, G.; Morris, R.E.; Serre, C. Metal-organic frameworks in biomedicine. Chem. Rev. 2012, 112, 1232-1268. [CrossRef] [PubMed]

11. Liu, B.; Shioyama, H.; Akita, T.; Xu, Q. Metal-organic framework as a template for porous carbon synthesis. J. Am. Chem. Soc. 2008, 130, 5390-5391. [CrossRef] [PubMed]

12. $\mathrm{Hu}, \mathrm{L}$; Chen, Q. Hollow/porous nanostructures derived from nanoscale metal-organic frameworks towards high performance anodes for lithium-ion batteries. Nanoscale 2014, 6, 1236-1257. [CrossRef] [PubMed]

13. Sun, J.-K.; Xu, Q. Functional materials derived from open framework templates/precursors: Synthesis and applications. Energy Environ. Sci. 2014, 7, 2071-2100. [CrossRef]

14. Das, R.; Pachfule, P.; Banerjee, R.; Poddar, P. Metal and metal oxide nanoparticle synthesis from metal organic frameworks (MOFs): Finding the border of metal and metal oxides. Nanoscale 2012, 4, 591-599. [CrossRef] [PubMed]

15. Lu, C.; Ben, T.; Xu, S.; Qiu, S. Electrochemical synthesis of a microporous conductive polymer based on a metal-organic framework thin film. Angew. Chem. Int. Ed. 2014, 53, 6454-6458. [CrossRef] [PubMed]

16. Hall, A.S.; Kondo, A.; Maeda, K.; Mallouk, T.E. Microporous brookite-phase titania made by replication of a metal-organic framework. J. Am. Chem. Soc. 2013, 135, 16276-16279. [CrossRef] [PubMed]

17. Cho, W.; Park, S.; Oh, M. Coordination polymer nanorods of Fe-MIL-88B and their utilization for selective preparation of hematite and magnetite nanorods. Chem. Commun. 2011, 47, 4138-4140. [CrossRef] [PubMed] 
18. Chaikittisilp, W.; Torad, N.L.; Li, C.; Imura, M.; Suzuki, N.; Ishihara, S.; Ariga, K.; Yamauchi, Y. Synthesis of nanoporous carbon-cobalt-oxide hybrid electrocatalysts by thermal conversion of metal-organic frameworks. Chem. Eur. J. 2014, 20, 4217-4221. [CrossRef] [PubMed]

19. Zhang, L.; Wu, H.B.; Madhavi, S.; Hng, H.H.; Lou, X.W. Formation of $\mathrm{Fe}_{2} \mathrm{O}_{3}$ microboxes with hierarchical shell structures from metal-organic frameworks and their lithium storage properties. J. Am. Chem. Soc. 2012, 134, 17388-17391. [CrossRef] [PubMed]

20. Lee, J.H.; Sa, Y.J.; Kim, T.K.; Moon, H.R.; Joo, S.H. A transformative route to nanoporous manganese oxides of controlled oxidation states with identical textural properties. J. Mater. Chem. A 2014, 2, 10435-10443. [CrossRef]

21. Wang, Z.; Li, X.; Yang, Y.; Cui, Y.; Pan, H.; Wang, Z.; Chen, B.; Qian, G. Highly dispersed $\beta$-NiS nanoparticles in porous carbon matrices by a template metal-organic framework method for lithium-ion cathode. J. Mater. Chem. A 2014, 2, 7912-7916. [CrossRef]

22. Comotti, A.; Bracco, S.; Sozzani, P.; Horike, S.; Matsuda, R.; Chen, J.; Takata, M.; Kubota, Y.; Kitagawa, S. Nanochannels of two distinct cross-sections in a porous Al-based coordination polymer. J. Am. Chem. Soc. 2008, 130, 13664-13672. [CrossRef] [PubMed]

23. Chaikittisilp, W.; Hu, M.; Wang, H.; Huang, H.-S.; Fujita, T.; Wu, K.C.-W.; Chen, L.-C.; Yamauchi, Y.; Ariga, K. Nanoporous carbons through direct carbonization of a zeolitic imidazolate framework for supercapacitor electrodes. Chem. Commun. 2012, 48, 7259-7261. [CrossRef] [PubMed]

(C) 2015 by the authors; licensee MDPI, Basel, Switzerland. This article is an open access article distributed under the terms and conditions of the Creative Commons Attribution license (http://creativecommons.org/licenses/by/4.0/). 